\title{
Reform of Paleontology Experiment Teaching for Geology Majors
}

\section{Jianpeng Chu ${ }^{*}$}

School of Resources and Environmental Engineering, Shandong University of Technology, Zibo, Shandong, 255049, China

\section{ARTICLE INFO}

Article history

Received: 26 February 2021

Revised: 28 February 2021

Accepted: 9 April 2021

Published Online: 16 April 2021

\section{Keywords:}

Experiment teaching

Paleontology

Experiment design

Teaching reform

\begin{abstract}
Due to the development of science and technology and the transformation of society's demand for talents of geology majors, many changes have taken place in the arrangement of teaching hours and teaching content of paleontology experiment teaching. The paleontology experiment teaching of geology majors has problems such as unreasonable experiment design, no independent experiment arrangement, single teaching method, absence of experiment contents, etc. the article believes that the reform should be made in the following aspects: setting up independent experiment teaching arrangement, improvement of experiment teaching design, continuing to improve the laboratory hardware and software construction, reform of teaching methods.
\end{abstract}

\section{Introduction}

Paleontology has played a central role in deciphering the history of the Earth, including the rates and dates of tectonic activity, evolution, climate change, and large impact events ${ }^{[1]}$. Paleontology is a core course in the science of Earth history, is also the basic core course of geology majors, and its experiment courses are important for cultivating students' ability to integrate theory with practice, to analyze and solve problems. Experiment teaching is an intermediate link between classroom teaching and field practice, paleontology is a course with plenty of practical courses, and its experiment teaching is particularly important. As an important component of paleontology teaching, experiment teaching has also received more attention of many paleontology teachers, who have done research and discussion on paleontology experiment teaching from different aspects. For example: The experiment teaching of paleontology should regard fossils as a starting point for research, students are guided to actively apply for scientific research projects so as to cultivate their innovative ability; The reform of paleontology experiment teaching for geology majors may take the following measures, such as the combination of theory teaching and experiment teaching, the complement of indoor experiment and field practice, and the improvement and expansion of teaching specimens. To the teaching method, some researchers introduced group competition into paleontology experiment teaching, which improves the initiative of students and increases their interest in learning. Some teachers emphasized the importance of laboratory construction in the process of paleontology experiment teaching, and believed

*Corresponding Author:

Jianpeng Chu,

School of Resources and Environmental Engineering, Shandong University of Technology, Zibo, Shandong, 255049, China;

E-mail:774207721@qq.com. 
that laboratory construction was the source of innovation ability training. It was not only necessary to strengthen the investment in hardware facilities such as experiment sites and equipment, but also to strengthen the construction of software such as high-level instructors, high-level scientific research support and advanced management concepts. These studies provide a useful reference for experiment teaching reform $^{[2-7]}$.

\section{The Current Situation of Paleontology Ex- periment Teaching}

\subsection{No Independent Experiment Teaching Pro- gram}

Paleontology once existed as an independent course in the training program of geology majors. With the development of society and the change of social demand for talents, some colleges and universities have carried out the teaching reform of paleontology course, paleontology and historical geology are merged into one course after the reform. At the same time, course hours and teaching content have been compressed in different degree. We take the teaching practice of paleontology of Shandong University of Technology as an example to analyze. In the current training program, paleontology and historical geology are offered as a course with 48 hours, of which 40 hours are taught theory in the classroom and 8 hours are arranged for in-class experiment teaching. The experiment teaching of paleontology was just arranged for in-class teaching, no independent experiment teaching program. Moreover, the experiment hours are too few and the task is relatively heavy, only eight hours are arranged for experiment teaching in the class to complete the task.

\subsection{Irrational Experiment Teaching Design}

The current experiment design is based on the geological age as a clue to organize the experiment content. Fossils are the study object of paleontology, the teaching practice of paleontology for many years' shows that the training based on fossils categories is very effective. The current experiment design cuts apart the internal connection of the same category fossils, which greatly reduces the training effect and increases the difficulty of students' learning. Taking cephalopod fossils as an example, the geological age of cephalopod fossils in our laboratory distributes from Ordovician to Cretaceous, which is arranged for four experiment classes. This has adverse effects on the observation of similar fossils, the analysis and summary of characteristics, and the improvement of identification techniques.

\subsection{Absence of Experiment Contents}

Micro fossils have broad application prospects in determining geological age, dividing and contrasting strata, restoring paleoenvironment and paleogeography, paleoclimate research, petroleum, coalfield geology, deep-sea exploration and so on. It is also an important part of paleontology courses. However, the treatment of micro fossils requires certain experiment conditions (stereo-microscope, acid treatment laboratory, etc.). Due to the limitation of objective conditions, the current experiment content does not include micro fossils.

\subsection{Teaching Method and Experiment Types are Single}

The current experiment teaching methods of paleontology are lack of experiment teaching design and positive interaction between teachers and students, students are passively accepted and the ability to mobilize students' enthusiasm is weak. The comprehensive application of teaching modes and teaching methods such as flipped classroom, split classroom and group collaborative inquiry learning are infrequent in the process of paleontology experiment teaching. From the perspective of experiment types, the current four experiments are all verification. The main task is to describe fossil characteristics, unit lithology of rock strata and rock equality. There is a lack of comprehensive and design experiment types. This kind of training is not difficult and lacks breadth and depth. Students' ability to comprehensively utilize and analyze knowledge cannot be exercised, knowledge and practice are disjointed. Students do not understand the specific purpose of learning knowledge, which is not conducive to students' mastery of theoretical knowledge and the cultivation of innovation ability.

\section{Reform Measures of Experiment Teaching}

In view of the existing problems of the current experiment teaching, combined with the training program of geology majors and the objective conditions of majors education, the reforms of experiment teaching are prepared from the following aspects ${ }^{[8-17]}$ :

\subsection{Setting up Independent Experiment Teaching Arrangement}

At present, there is no separate experiment teaching arrangement in the experiment teaching of paleontology, and the experiment teaching is mainly solved by in-class experiments. But in-class experiment class hours are limited, time is too short, can not reach good teaching effect. The

DOI: https://doi.org/10.26549/jetm.v5i1.6470 
teaching practice of paleontology of Shandong University of Technology was taken as an example, only 4 times 8 hours (2 hours/times) are arranged for in-class experiment teaching. Some paleontology experiments need a long time, for example, micro fossils needs an acidolysis process. In order to ensure the teaching effect, it is necessary to set up an independent experiment teaching arrangement of paleontology in the major training program. Paleontology can also set up an experiment teaching arrangement with stratigraphy, and the time is about 2 weeks. Setting up an independent experiment teaching arrangement will greatly improve the current experiment teaching. One of the problems existing in the current experiment teaching is that the class hours are too few. Due to the course reform, the major's course hours are generally compressed. In this context, the teaching hours can only be adjusted and increased in paleontology course itself. After setting up an independent experiment teaching arrangement, the problem of too little course hours is completely solved. It also provides the premise for solving other problems.

\subsection{Improvement of Experiment Teaching Design}

Paleontology is a discipline with strong practicality and experience. Fossils are the research object of paleontology and the main experiment teaching content of paleontology. Therefore, the description and classification of various categories of fossils, the specific genus and species characteristics should also be observed and studied in the experiment class. Past experience tells us, the training based on fossils categories is very effective. The new structure of the experiment content based on the ancient fossils categories note based on the geological age should be set up. According to the new structure, fossil specimens are divided into trilobites, penstones, cephalopods, corals, brachiopods, bivalves, plant fossils, microfossils and other nine categories. The experiment contents are arranged according to the categories. Students are required to describe the main characteristics of fossils, learn to identify the main standard fossils, master the geological age of specific fossils and the representative environment; At the same time, the purpose of the experiment is to make students describe describe the fossils of different times, understand the lithology of the main lithostratigraphic units and the evolution process of the sedimentary facies represented by them into a comprehensive explanation of the fossil characteristics, lithology, lithofacies, sedimentary environment and geological age of the strata, and change the experiment type from simple verification type to comprehensive and design, and pay attention to the cultivation of students' research ability and innovation ability.

\subsection{Reform of Teaching Methods}

We should actively explore the application of mixed teaching methods consisting of flipped classroom, peer-topeer classroom and group collaborative inquiry learning in experiment courses, and actively learn from successful teaching methods such as group competitions in other universities.

\subsection{Continue to Improve the Laboratory Hard- ware and Software Construction}

Laboratory construction is the necessary guarantee to improve the quality of students' training, and perfect laboratory conditions are also the basis of innovative education for students. In terms of hardware, it needs to be equipped with ventilation cabinets, vacuum cabinets, stereo microscopes, grinders and other necessary equipment to increase the content of micro paleontology in the experiment design; In terms of software, the construction of teacher team should be strengthened.

\section{Conclusion}

Paleontology is the basic course of geology majors, the experiment teaching of paleontology connects the classroom with the field practice, and it is the key link of implementing quality education and cultivating geological talents with practical ability and innovative spirit. The reform of the contents, design, methods and means of experiment teaching is an important way to achieve the goal of talent training. The paper summarizes the problems in the process of paleontology experiment teaching practice such as single teaching method and experiment type, no independent experiment teaching program, etc. It is believed that the experiment content should be redesigned and a new structure should be established from the aspects of setting up independent experiment teaching arrangement, increasing the number of experiment hours, organizing the experiment content based on fossil categories, etc.

\section{References}

[1] Teaching Paleontology [EB/OL].https://serc.carleton. edu/NAGTWorkshops/paleo/index.html.

[2] WANG Hai-zhou, ZHU Cai-fa, ZHANG Zidong. Thoughts on the International Innovation of Paleontology Course[J].Education teaching forum,2020(06):109-110.

[3] XING Zhi-feng, ZHENG Wei, WANG Min.The Factor and Channel to Develop Student's Creative Ability in the Paleontology[J].Education modernization,2016,3(39):200-201. 
[4] LI Wei, CHEN Min, ZHOU Shumin, et al.Teaching Practice of the Mixed Course of Paleontology and Geohistory[J].The Guide of Science \& Education,2020(08):160-162.

[5] FENG Shuo, TIAN Ji-jun, LI Xin, et al. Discussion on the Teaching Practice of Paleontology Course in Resources Exploration Engineering Major[J]. Education teaching forum,2020(48):233-235.

[6] Hans G. Machel. Roadkill as Teaching Aids in Historical Geology and Paleontology. 2018, 44(3):270276.

[7] Leif Tapanila. FossilPlot, an Excel-based Computer Application for Teaching Stratigraphic Paleontology Using the Sepkoski Compendium of Fossil Marine Genera. 2018, 55(2):133-137.

[8] Aguirre-Urreta, Beatriz, Camacho, Horacio H.. Martn Doello Jurado and the teaching of Paleontology in the University of Buenos Aires. 2011, 68(3):329-336.

[9] Brower James C.. A statistically oriented approach for teaching principles of paleontology. 1976, 2(1):33-40.

[10] William H. Matthews. Marine Ecology as an Aid in Teaching Invertebrate Paleontology. 1957, 31(2):463-
464.

[11] Bradford Willard. Teaching Vertebrate Paleontology. 1928, 36(3):261-264.

[12] Paleontology; New Paleontology Study Findings Have Been Reported by Investigators at University College Cork (Taphonomic Experiments Resolve Controls On the Preservation of [13] Ludwig-Maximilians-Universität München; Paleontology: Experiments in evolution. 2019:282-285.

[14] Paleontology; Investigators from Sorbonne University Report New Data on Paleontology (Atomic scale transformation of bone in controlled aqueous alteration experiments). 2019:411-413.

[15] Martin Thomas. Paleontology. Early mammalian evolutionary experiments.2006, 311(5764):11091110.

[16] Seedlings Are Living Experiment of Dead Age. 1950, 58(2):28-28.

[17] Paleontology; Researchers from Yale University Report on Findings in Paleontology (The Role of Experiments in Investigating the Taphonomy of Exceptional Preservation),2016:1078-1080. 